\title{
Child Abuse and Neglect: Usefulness of the Animal Data
}

\author{
Dario Maestripieri \\ Emory University
}

\author{
Kelly A. Carroll \\ Berry College
}

\begin{abstract}
This article reviews and critically discusses the relevance of animal data to research on child abuse and neglect. Although parental investment theory can be useful in investigating the adaptiveness, if any, of child abuse and neglect, the evolutionary approach also has some limitations. The most suitable animal models for investigating the psychosocial processes underlying child abuse and neglect are probably found among the nonhuman primates. Whereas the heuristic value of social deprivation paradigms may be limited, recent studies suggest that the spontaneous occurrence of infant maltreatment in monkeys may be the closest approximation to child maltreatment provided by nonhuman animals. The investigation of adaptive and maladaptive processes in the parenting behavior of socially living nonhuman primates can inform research on child abuse and neglect and allow investigators to conduct studies that would be difficult or impossible in humans.
\end{abstract}

Every year, thousands of infants and children receive medical treatment for deliberately inflicted burns, fractures, cerebral hemorrhages, or malnutrition. In 1993, child abuse and neglect resulted in 2,000 deaths and 370,000 substantiated physical injuries and sexual offenses in the United States alone (National Center on Child Abuse and Neglect, 1995). Although research with animal models figures prominently in the study of other major public health threats such as AIDS, cancer, drug abuse, and homicide, little research with animal models of child abuse and neglect is currently being conducted.

In the 1970s and 1980s, the systematic application of evolutionary theory to the study of animal and human behavior focused attention on animal phenomena that shared some similarities with child abuse and neglect (e.g., Hausfater \& Hrdy, 1984). Although the animal data were instrumental in developing predictions that were subsequently tested with human data (e.g., Daly \& Wilson, 1981; Lenington, 1981; Lightcap, Kurland, \& Burgess, 1982), the evolutionary analyses of child abuse and neglect did not prompt the development of animal models of child abuse and neglect.

In the same period, psychologists and biologists interested in understanding the causation of child abuse and neglect focused

Dario Maestripieri, Department of Psychology and Yerkes Regional Primate Research Center, Emory University; Kelly A. Carroll, Department of Psychology, Berry College.

This work was supported by grants from the Biomedical Resources Foundation, the Harry Frank Guggenheim Foundation, and the National Institutes of Health (NIH) Grant MH56328. Partial support was also provided by NIH Grant RR-00165. The Yerkes Regional Primate Research Center is fully accredited by the American Association for Accreditation of Laboratory Animal Care. We thank Dante Cicchetti, Lynn Fairbanks, and Kim Wallen for helpful comments on this article.

Correspondence concerning this article should be addressed to Dario Maestripieri, Yerkes Regional Primate Research Center, Emory University, 2409 Taylor Lane, Lawrenceville, Georgia 30043. Electronic mail may be sent to psydm@emory.edu. their attention on nonhuman primates (hereafter primates) as potential animal models for this phenomenon (e.g., Reite \& Caine, 1983). In the previous decade, Harry Harlow and coworkers had shown that infant abuse and neglect could be induced in the laboratory by separating rhesus monkey (Macaca mulatta) infants from their mothers and rearing them in social isolation (Harlow \& Harlow, 1962; Ruppenthal, Arling, Harlow, Sackett, \& Suomi, 1976). Social deprivation in monkeys received a great deal of interest as an experimental paradigm for studying the causes of child abuse and neglect as well as for improving prevention and treatment (e.g., Horenstein, 1977). Despite the initial optimism concerning the value of the primate data, however, the research on infant maltreatment in primates has made little progress since Harlow. In fact, when the limitations of the social deprivation model became apparent, no systematic effort was made to revise this experimental paradigm or to develop an alternative model.

The aim of this article is to critically evaluate the relevance of animal data to research on child abuse and neglect. After a brief overview of some major etiological models of child abuse and neglect, we review the basic theoretical premises of evolutionary analyses of child maltreatment and some of the animal data on which these premises are founded. Then we critically review the social deprivation model of child abuse and neglect in primates and compare it with a different primate model: the spontaneous occurrence of infant abuse and neglect in monkeys living in stable and undisturbed social groups. For each model, we review the data available, the interpretation of the findings, and their relevance to child abuse and neglect (sexual abuse is not considered in this article). The discussion of the two primate models is introduced by some general considerations concerning the selection of an animal model for child abuse and neglect and concludes with some directions for future research on infant maltreatment in primates.

\section{Etiological Models of Child Abuse and Neglect}

Since the phenomenon of child maltreatment was first systematically investigated in the 1960s (Kempe, Silverman, Steele, 
Droegemueller, \& Silver, 1962), numerous attempts have been made to understand the causes of its occurrence. Early studies emphasized the view that abusive and neglectful parents suffered from some form of psychopathology or personality disturbance (Kempe et al., 1962; Steele \& Pollack, 1968). Subsequent studies, however, found that abusive parents could not be reliably identified from nonabusive parents on the basis of personality measures alone (Gelles, 1973; Spinetta \& Rigler, 1972; Wolfe, 1985). Sociological models of child maltreatment emphasized the role of environmental factors such as economic deprivation and lack of social support (Garbarino, 1977; Gelles, 1973; Gil, 1970). It was later recognized, however, that socioeconomic factors offer only limited predictive value regarding dysfunctional parent-child relationships (e.g., Wolfe, 1987). More recent social interactional and developmental-ecological models have focused on the interactional process between parent and child, within the context of the family and the larger social structure and in light of the parent's developmental history (e.g., Belsky, 1980, 1993; Cicchetti \& Rizley, 1981). There is now a consensus that child maltreatment is a complex and heterogeneous phenomenon that is determined by factors operating at multiple levels of analysis (Belsky, 1993; Cicchetti \& Toth, 1995; Wolfe, 1987).

\section{Animal Data and Evolutionary Analyses of Child Abuse and Neglect}

From an evolutionary perspective, child abuse and neglect could be viewed as a form of discrimination against offspring in circumstances unfavorable to parental care (e.g., when parenthood confidence is low, offspring quality is poor, or parental resources are scarce). The evolutionary predictions tested with the human data have been mostly derived from parental investment theory and data obtained from fish, birds, and nonprimate mammals. Therefore, before discussing the findings of evolutionary analyses of child maltreatment and the implications of this approach, we briefly review this theory and some of the relevant animal data.

Parental investment theory predicts that parents should terminate investment in their young whenever the fitness costs associated with parental care outweigh its benefits (Trivers, 1972, 1974). The fitness costs of parental care are measured in the negative effect that expenditure on the offspring has on the parent's probability of survival and future reproduction. The benefits of parental care refer to the effect that parental expenditure has on the offspring's probability of survival and future reproduction and, therefore, on the offspring's ability to propagate the parent's genes in future generations. Thus, from the perspective of parental investment theory, offspring neglect or destruction reflects termination of parental expenditure on the offspring in circumstances in which such expenditure is no longer advantageous. The implication of this view is that offspring neglect or destruction is under some degree of genetic control and that the genes controlling such behaviors have spread in the population as a result of natural selection.

Parental abandonment of the offspring and offspring destruction are relatively common phenomena in several animal taxa. With the exception of particular circumstances (see CluttonBrock, 1991), parents are selected to invest only in their own offspring and to reject the young of unrelated individuals. The ability to discriminate against foreign eggs or offspring is especially likely to have evolved in species and individuals in which the risk of adoption is substantial. For example, in birds that incubate eggs in dense aggregations of nests or in a communal nest, females attempt to destroy or evict the eggs laid by other females (Birkhead, 1978; Mumme, Koenig, \& Pitelka, 1983; Vehrencamp, 1977). In species with internal fertilization (e.g., birds and mammals), particularly those in which females mate with multiple males, parenthood confidence is lower for males than for females (Clutton-Brock, 1991). Therefore, in these species, males are more likely than females to neglect or destroy young, and the probability of offspring neglect or destruction will be higher the lower the confidence of paternity. For example, in rodents, the probability that an adult male will destroy a litter is affected by the amount of time elapsed since the male's last mating episode and, therefore, by the probability that this male sired the litter (vom Saal \& Howard, 1982). In mammals, destruction of unrelated offspring may also be effective in terminating lactational amenorrhea and promoting resumption of female fertility (Hrdy, 1979).

In addition to low parenthood confidence, any situation that reduces the probability of survival and future reproduction of the offspring or the parent will also alter the cost-benefit ratio of parental care and potentially result in offspring neglect or destruction. Such situations include poor offspring quality (either congenital defects or damage inflicted by external agents), injury or sickness of the parent, and environmental changes of various kinds, ranging from abrupt climatic changes to predator attacks or food shortage. In fish and birds, termination of parental investment under conditions of food shortage or predator disturbance takes the form of brood desertion or egg cannibalism (Mock, 1984). Brood desertion is more likely to occur early in the breeding season, when parents have not yet invested much in their eggs and they have time to produce another brood (Mock \& Parker, 1986). Brood desertion can also be induced by artificial reduction of brood size. Specifically, when brood size falls below a threshold value, it is more advantageous for parents to abandon or cannibalize their young and start over with a new brood than to continue their investment (Armstrong \& Robertson, 1988; Dominey \& Blumer, 1984; Mrwoka, 1987).

In many mammals, termination of parental investment in unfavorable environmental conditions takes the form of abortion, reabsorption of the litter, desertion of the young, or cannibalism (Wasser \& Barash, 1983). In species with multiple offspring, offspring neglect, cannibalism, or both also occur when litter size is significantly reduced. For example, in coypu (Myocastor coypus), a rodent living in South America, young females abort small litters during the last part of pregnancy, whereas large litters are retained (Gosling, 1986). Similarly, in certain carnivores, loss of some of the young will result in abandonment of their surviving siblings (Tait, 1980; Wickler \& Seibt, 1983). Offspring abandonment or cannibalism can also occur when litters are significantly larger than their optimum (Day \& Galef, 1977; Gandelman \& Simon, 1978). This situation may arise when mothers are unable to sustain the lactational costs of the litter that they originally produced because of adverse environmental circumstances (Mendl, 1994). For example, when mouse and rat mothers are food restricted during early lactation, they 
cannibalize their pups one at a time as lactation progresses, thereby reducing litter size and gaining an additional food source (König, 1989; Maestripieri, 1991; McClure, 1981). In laboratory rodents, environmental perturbations such as flooding of the home cage or introduction of a strange adult male may also induce mothers to cannibalize their pups. For example, rat and mouse mothers may cannibalize their pups when they have been unsuccessful in protecting them from male aggression. Once pup infanticide by the male has begun, mothers will abruptly cease their attacks toward the male and join the male in the consumption of the litter (see Maestripieri, 1992).

The overview of the animal data on offspring neglect and destruction suggests that whenever conditions are no longer favorable to parental care, the first option available to parents is to abandon their offspring. Abandonment entails immediate benefits to the parent-the immediate termination of any expenditure on the offspring - and no costs (e.g., in terms of any expenditure of energy or risk of injury that may be involved in destroying the offspring). In addition, abandonment of live offspring leaves open the possibility that the young will be adopted and raised by other individuals. Animal parents destroy their offspring if abandonment is not feasible or if offspring destruction brings about additional benefits to the parent relative to abandonment (e.g., use of the offspring as a food source [cannibalism]).

The predictions of parental investment theory fit well with human data concerning child maltreatment perpetrated by parents with poor or unstable resources or suffered by children with physical or mental handicaps (Daly \& Wilson, 1981; Lenington, 1981; Lightcap et al., 1982). Some initial studies found that risk of maltreatment was higher in households with stepparents than in those with both natural parents, suggesting that, as with animals, genetic relatedness is an important factor (Daly \& Wilson, 1981; Lenington, 1981; Lightcap et al., 1982). However, a recent study showed that biological parents were more likely to engage in severe child abuse than stepparents, thus undermining the value of the adaptive explanation (Malkin \& Lamb, 1994).

The finding that infants and young children are at greater risk of severe abuse than older children is also consistent with parental investment theory (Lenington, 1981; Malkin \& Lamb, 1994), which predicts that investment should be terminated as early as possible. However, the association between young infant age and abuse could also result from the fact that infants and young children are more vulnerable to severe injury than older children. Finally, the observation that postfertile (more than 55 years of age) women are less likely to abuse their children than fertile (12-54 years of age) related women is also consistent with evolutionary principles (Malkin \& Lamb, 1994). In fact, younger women have more reproductive opportunities than older women in their lifetime. Again, however, the different probability of abuse in relation to female age could result from factors other than reproductive potential that vary as a function of age (e.g., availability of resources).

Although in some cases the findings of evolutionary analyses were also predicted by sociological theories of child maltreatment, evolutionary and sociological explanations are not mutually incompatible, because they focus on different levels of analysis (adaptive function vs. causation). Even when the adaptive hypotheses were not supported by the data (e.g., Malkin \& Lamb, 1994), the evolutionary approach had heuristic value in that it stimulated research and generated knowledge concerning aspects of child maltreatment that had not been previously investigated. However, some words of caution concerning evolutionary analyses of child maltreatment are in order.

First, a number of child abuse and neglect cases may not readily fall into any of the categories encompassed by parental investment theory. For example, child maltreatment may be perpetrated by biological parents in situations in which neither parents nor children have any obvious handicaps. Second, whereas child neglect intrinsically reflects a reduction in parental expenditure on the offspring, this is not necessarily the case for physical abuse. In fact, only a minority of abuse cases are fatal, and abusive parents may inflict injuries on their children while continuing their economic and socioemotional investment in them. This raises the possibility that evolutionary principles may be more directly applicable to child neglect than to abuse. In this respect, it is interesting to note that poverty is more relevant to the risk of neglect than abuse (Daly \& Wilson, 1981). Finally, it must be remembered that hypotheses concerning the adaptive significance of a trait imply that the trait is genetically controlled. The vast heterogeneity of child maltreatment forms and of the contexts of maltreatment suggests that this phenomenon is unlikely to be under significant genetic control. Some evolutionary psychologists, however, have argued that the adaptiveness of child maltreatment may be apparent in the psychological dispositions and motivational systems conducive to maltreatment rather than in the behavior itself (Daly \& Wilson, 1981).

\section{Animal Models of Child Abuse and Neglect}

An ideal animal model of child abuse and neglect would be a phenomenon occurring in another animal species or taxon that has the same biological function (or lack thereof) and is regulated by the same mechanisms as child abuse and neglect. Such a phenomenon would give scientists the opportunity to investigate the causes and consequences of child abuse and neglect without the ethical and practical limitations that accompany research with humans.

When one considers the choice of an animal model for child abuse and neglect, it is important to clarify what aspect of this phenomenon one intends to model in the animal. For example, if one is interested in pursuing the evolutionary approach and investigating the adaptive function, if any, of child maltreatment, one could use almost any of the animal species mentioned in the previous section. The species whose life history, ecological environment, and parental care systems are most similar to those of humans (e.g., some of the mammals, particularly the primates) would probably be the most suitable subjects, but useful information could be derived as well from other animals such as fish and birds. For example, one could experimentally investigate a variety of environmental situations that lead to termination of parental care in these animals and use the evidence to generate hypotheses that could be tested with the human data.

If child maltreatment, however, is for the most part a pathological phenomenon resulting from the dysfunction of mechanisms and processes underlying human parenting, the best animal mod- 
els would probably be found among the species that are most similar to humans in terms of how parenting is regulated. In most nonmammalian species, particularly nonprimates, social, experiential, and cognitive variables have a limited influence on parental care, the latter being under strong genetic and neuroendocrine control (Rosenblatt \& Snowdon, 1996). Primates, however, and most notably Old World monkeys and apes, share with humans many psychological, experiential, and social influences on parenting. In particular, regardless of specific differences in the patterns of interaction between parents and offspring, emotional reactions to the risk of losing the infant, perception of infant vulnerability, and other emotional and cognitive correlates of parenting are likely to be very similar (Maestripieri, 1993a, 1993b, 1995a, 1995b, 1996; Maestripieri \& Call, 1996). Therefore, primates provide the opportunity to investigate the functional significance of child abuse and neglect as well as some of the social, experiential, and cognitive processes underlying this phenomenon.

The choice of an animal species or taxon is only the first step in developing an animal model of child abuse and neglect. In the same animal species, there may be more than one phenomenon sharing similarities with child abuse and neglect. The phenomenon chosen to model child abuse and neglect is crucial, because the kind of model being used will influence the interpretation of the data and the validity and generalizability of the research questions addressed. Extrapolations from primate data to human child abuse and neglect have been conducted from at least two different primate phenomena: the experimental induction of infant abuse and neglect with social deprivation paradigms and the study of the spontaneous (i.e., not experimentally induced) occurrence of infant abuse in group-living monkeys.

\section{The Social Deprivation Model}

\section{The Data}

In the early 1960 s, Harlow and colleagues reported that most rhesus monkey females who had been separated at birth from their mothers and raised on inanimate surrogates or alone in wire cages at the Wisconsin Primate Laboratory exhibited a variety of negative responses toward their first-born infants, including neglect, violent rejection of infant contact, hitting, biting, stepping and jumping on infants, mutilation, and, in some cases, infanticide (Harlow \& Harlow, 1962; Seay, Alexander, \& Harlow, 1964). Subsequent research conducted in the same and in other laboratories identified several factors that affected the occurrence of inadequate maternal care in these "motherless mothers."

Early studies showed that mothers reared with peers were more likely to exhibit adequate maternal care than mothers reared alone in a wire cage or with a cloth surrogate (Arling \& Harlow, 1967; Harlow, Harlow, Dodsworth, \& Arling, 1966; Harlow \& Seay, 1966). A subsequent study indicated that, among peer-reared mothers, females who had reacted to separation from peers with depression were more likely to subsequently display inadequate maternal care than females who had not become depressed in response to separation (Suomi \& Ripp, 1983). In addition to rearing experience, maternal parity affected the probability of displaying adequate maternal care. Spe- cifically, the proportion of mothers showing adequate maternal care increased with their successive infants, and as little as 48 hr of contact with the first infant was very likely to be followed by adequate care of the following infant (Harlow et al., 1966; Ruppenthal et al., 1976). Research conducted in Holland also showed that observation of maternal care reduced the probability of infant abuse and neglect (Dienske, van Vreeswijk, \& Koning, 1980). Some tactile experience with infants, however, was necessary to hold the infant properly, even for mothers with visual experience of maternal care. The influence of age of the mother and sex of the infant on infant abuse and neglect was also examined. Females who neglected their infants had a higher mean age at first delivery than females who abused their infants (Ruppenthal et al., 1976). Although it was initially reported that male infants were more likely to be abused than female infants (Ruppenthal et al., 1976), this finding could not be replicated with a different sample of motherless mothers ( $\mathrm{Su}$ omi, 1978; Suomi \& Ripp, 1983).

\section{Interpretation of the Findings}

Altogether, the findings obtained with rhesus motherless mothers led to a series of generalizations concerning the regulation of maternal care in monkeys and several explanations for the occurrence of infant abuse and neglect. Initially, it was argued that infant abuse and neglect resulted from lack of exposure to adult models during development and consequent failure to learn species-specific mothering skills (Seay et al., 1964). Later it was proposed that the exposure to adult models was not necessary: Any contact with conspecifics, either with peers before adulthood or with one's own infant later in life, would greatly increase the probability of adequate maternal care (Ruppenthal et al., 1976). More recently, it was argued that the neurobiological trauma associated with disruption of attachment or aberrant experience early in life may have interfered with subsequent physiological maturation and impaired the expression of normal parenting behavior at a later date (Reite, 1987; Reite \& Capitanio, 1987). Thus, the common theme of most interpretations of infant abuse and neglect by motherless mothers was the importance of early social experience for maternal behavior (but see Suomi \& Ripp, 1983).

Some methodological aspects of the research with motherless mothers and a more detailed analysis of its findings cast doubt on some of its generalizations concerning the determinants of normal and abnormal maternal behavior. For example, regarding the role of experience-or lack thereof-as a determinant of inadequate maternal behavior, it must be noted that the increase in the proportion of adequate maternal care with successive infants was solely due to a reduction in indifference and neglect and not in abuse, which remained constant with successive offspring (Ruppenthal et al., 1976). Similarly, peer rearing was associated with a lower occurrence of infant neglect but not of abuse (Suomi, 1978). These findings indicate that the rearing environments of motherless mothers or their experience with infants did not play a significant role in the occurrence of infant abuse and suggest that infant abuse and neglect may be different phenomena.

The central tenet of the social deprivation model - that the developmental history of motherless mothers accounts for their 
inadequate maternal care-is seriously questioned when the effects of social housing conditions on infant abuse and neglect in primates are considered. A number of studies of monkeys and apes conducted in the 1960s through the early 1980s showed that infant abuse was much more likely to occur in individually caged mother-infant pairs than in group-living individuals and in smaller cages than in larger cages, irrespective of the developmental history of the individuals (rhesus macaques: Hinde \& Spencer-Booth, 1967; pigtail macaques (Macaca nemestrina): Castell \& Wilson, 1971; Jensen, Bobbitt, \& Gordon, 1969; Wolfheim, Jensen, \& Bobbitt, 1970; Japanese macaques (Macaca fuscata): Negayama, 1981; squirrel monkeys (Saimiri sciureus): Kaplan, 1972; chimpanzees (Pan troglodytes) and gorillas (Gorilla gorilla): Davenport, 1979; Davenport \& Rogers, 1970; Nadler, 1980, 1983; Rogers \& Davenport, 1970). When the animal housing conditions at the Wisconsin Primate Laboratory were improved in the late 1970s, significant changes in the incidence of infant abuse and neglect by motherless mothers were noted. Suomi (1978) initially reported that all motherless mothers, regardless of their rearing environment, displayed adequate maternal care if allowed to live in stable social groups during pregnancy and after delivery. Suomi and Ripp (1983) subsequently reported that the prevalence of adequate maternal care by motherless mothers, although much improved, was still $20 \%$ below that of mothers that had been reared by their own mothers. A more detailed data analysis revealed that the difference in prevalence of inadequate maternal care between motherless and mother-reared mothers was accounted for by a few motherless mothers that had been repeatedly separated from their peers and had reacted with depression to separation. Without this subgroup of individuals, the group-living motherless mothers were statistically indistinguishable from the motherreared mothers.

Comparison of mother-infant interactions in different housing conditions indicates that the housing environment can override the effects of the mother's developmental history on maternal care, even when this includes traumatic events such as maternal separation and isolation rearing. Although studies of motherless mothers have made the important contribution of demonstrating the dramatic consequences of social deprivation for adult behavior, they have failed to clearly assess the relative contribution of social deprivation during infancy versus the living conditions of the adult individual in inducing infant abuse and neglect.

\section{Relevance to Child Maltreatment}

In the early studies of infant abuse and neglect in rhesus motherless mothers, the implications of this research for child abuse and neglect were not discussed. In the late 1970s and $1980 \mathrm{~s}$, however, the findings obtained with motherless mothers were thoroughly reviewed and explicitly linked to the human phenomenon. For example, Horenstein (1977) suggested that Harlow's studies "not only provide insight into the dynamics of the abusive parent, but hint at the essential treatment and rehabilitation programs necessary for these parents' (p. 563). Suomi (1978) also noted that parallels to specific findings regarding rhesus motherless mothers could be found throughout the human literature. However, as the effects of housing condi- tions on infant abuse and neglect by motherless mothers became clearer, Suomi and Ripp (1983) more cautiously stated that this phenomenon shared some general principles (e.g., the presence of multiple determinants), rather than specific findings, with child abuse and neglect.

One concern regarding the validity of the social deprivation paradigm as a model for child maltreatment is the magnitude of the trauma associated with early maternal separation and rearing in social isolation. The degree of deprivation of social, sensory, and motor stimuli experienced by these monkeys is rarely experienced by humans. Therefore, the relevance of $a b-$ normal parenting induced by extreme social deprivation for understanding the etiology of child abuse and neglect is unclear, because the two phenomena very likely have different determinants.

Another concern regarding the social deprivation model is its lack of specificity. Separation from the mother and rearing in isolation resulted in extensive social pathology not limited to parenting. Motherless mothers and other socially deprived rhesus monkeys showed abnormalities in virtually every type of social interaction, including contact, proximity, grooming and play (Sackett, 1965), aggression and avoidance (Mitchell, Raymond, Ruppenthal, \& Harlow, 1966), mating (Senko, 1966, as cited in Suomi, 1978), and communication (Miller, Caul, \& Mirsky, 1967). Therefore, early social deprivation provides, at best, a primate model for social pathology and not one specific to child abuse and neglect.

The primary emphasis of the social deprivation model on the developmental history of abusive mothers also greatly limits its generalizability to child abuse and neglect. Research on child abuse has shown that information on the parent's developmental history alone is a poor predictor of abusive behavior. Although abusive parents often report retrospectively that they were themselves abused as children or were raised in an atmosphere of violence and low affectional expression, only a small minority of adults who report being abused as children are abusive toward their own children (Straus, Gelles, \& Steinmetz, 1980; Widom, 1989). The parent's early adverse experiences and learning history are best regarded as potentially predisposing characteristics for child abuse and neglect (Belsky, 1993). This could be true for monkeys as well as humans, and therefore the information provided by social deprivation studies may be important. However, without information on the interactional process between parent and child within the context of their family and the larger social structure, the parent's developmental history alone may be of little help in understanding the causes of child abuse or neglect.

\section{Infant Abuse and Neglect in Group-Living Monkeys}

\section{Identification of the Phenomenon}

Virtually all Old World monkeys are highly social animals that live in groups composed of multiple females with their offspring and one or more adult males (Smuts, Cheney, Seyfarth, Wrangham, \& Struhsaker, 1987). Reports of infants being injured or killed by conspecifics other than the infant's parents are not uncommon both in captivity and in the wild. The incidence of aggression toward infants varies considerably among 
different species and among individuals of the same species. In species in which adult males take over groups of females from other males, the incoming males may attempt to kill the infants sired by the resident males (Struhsaker \& Leland, 1987). In species in which adult females have highly competitive relationships, females may attack or kidnap the infants of unrelated females (Maestripieri, 1994b). Aggression toward infants by individuals other than their parents is, in most cases, an adaptive phenomenon accounted for by patterns of competition between males or females, which in turn depend on the ecology and social organization of the species (Maestripieri, 1994b). This type of competition-related aggression toward monkey infants may be largely irrelevant to understanding child abuse and neglect in humans, because most child maltreatment is perpetrated by a child's biological parents (e.g., Rogosch, Cicchetti, Shields, \& Toth, 1995).

Therefore, in investigating the occurrence of infant maltreatment in group-living monkeys, it is crucial that aggression received by infants from other conspecifics be separated from maternal abuse and neglect of offspring. Unfortunately, this has not always been the case in previous attempts to extrapolate from primate data to the human phenomenon. In the early 1980s, some attempts were made to obtain information on infant abuse from the medical records of primate research facilities (Caine \& Reite, 1983; Schapiro \& Mitchell, 1983). In the majority of cases, however, the only information provided by the medical records concerned injuries inflicted to infants by individuals other than the mother in circumstances unknown. The interpretation of these data and the claims made concerning parallels between the primate data and the literature on child abuse and neglect were largely unwarranted. To give one example, when the medical records of the California Primate Center indicated that in more than half of the cases in which monkey infants were injured, their mothers were in poor physical health (or, on some occasions, were themselves being treated for wounds), Schapiro and Mitchell (1983) concluded that in monkeys, as in humans, stress on the parent can increase the probability of infant abuse. An alternative and more parsimonious explanation, however, is that mothers in poor health were less efficient in protecting their infants from other group members and that, in some cases, both mothers and infants received aggression from these individuals.

The study of group-living primate mothers that abuse or neglect their infants is more likely to provide information relevant to child abuse and neglect than the study of aggression received by infants from other individuals. Before reviewing the information concerning this phenomenon, we must tackle the issue of defining neglect and abuse in monkeys. A number of studies of mother-infant interactions in captivity and in the field have shown that monkey mothers vary greatly from one another in the amount of time they spend in contact with their infants, the frequency with which they nurse them, and how well they protect them from other conspecifics (Fairbanks, 1996). Although it is empirically possible to identify, at any infant age, threshold values for measures of contact, nursing, or maternal protectiveness below which the infant's survival is jeopardized and to use these values as an objective behavioral criterion for neglect (Fairbanks \& McGuire, 1995), this criterion has rarely been applied in practice. A more conservative approach used to iden- tify neglect is to focus on abandonment (i.e., the complete cessation of maternal interactions with the infant). Maternal abandonment of a young infant results in infant death unless the infant is adopted by another lactating female. Abandonment of a live infant can also be reliably distinguished from abandonment subsequent to infant death, because monkey mothers normally carry their dead infants for hours or days.

The identification of abuse is more straightforward than that of neglect because most behavioral patterns of abuse are qualitatively different from any other behavior in the maternal repertoire. Similar to the motherless mothers studied in the Wisconsin laboratory, abusive mothers living in social groups drag their infants by their tail or legs while walking or running, push them against the ground with their hands, or step or sit on them (Maestripieri, 1998; Troisi \& D'Amato, 1983). A number of studies in captivity and in the field have shown that most mothers never display any of these behaviors at any time during infant development (e.g., Hinde \& Spencer-Booth, 1967). Specifically, although monkey mothers sometimes slap or bite their infants during weaning-related conflicts, the just-described patterns of behavior do not occur in this context. Most patterns of infant abuse are also different from those of the aggressive repertoire of adult monkeys, suggesting that infant abuse cannot be interpreted as a form of misplaced aggression. The aggressive behavior of adult individuals mostly consists of biting, whereas abusive mothers display patterns of behavior (e.g., dragging or throwing) that are commonly used with inanimate objects (Troisi \& D'Amato, 1983). Moreover, whereas aggressive behavior is usually accompanied by signs of arousal such as piloerection and screaming, this is not the case for infant abuse (Troisi \& D'Amato, 1983).

The consequences of abuse patterns such as dragging or stepping on the infant may range from infant distress calls without any observable injury to infant death. Although the identification of infant abuse may be more straightforward when abuse results in injury or death, recent observations indicate that cases of mild and severe infant abuse differ in the frequency of occurrence of abuse rather than in its physical patterns (Maestripieri \& Carroll, in press). Therefore, even if dragging or stepping on the infant does not necessarily result in injury or death, such behaviors should be identified as abuse. The identification of infant abuse on the basis of maternal behaviors that are likely to cause harm to infants rather than on the basis of demonstration of infant injury is directly comparable to recent definitions of child abuse in humans (Barnett, Manly, \& Cicchetti, 1993). It must be emphasized that the use of the term abuse reflects a human value judgment and that, although the primate phenomenon could be described via a different terminology, the same term is used for primates and humans to help better communicate the relevance of the animal data for the human case.

\section{The Data}

Information on the spontaneous occurrence of infant abuse and neglect in group-living monkeys has been obtained from two sources: analysis of animal reproductive and clinical histories from long-term colony records and direct observation and quantification of mother-infant interactions. Maestripieri, Wallen, and Carroll (1997a; b) used the long-term colony records 
of the Yerkes Regional Primate Research Center to investigate the occurrence of infant abuse and neglect in group-living pigtail macaques and sooty mangabeys (Cercocebus atys) during a period of 30-35 years. The data set consisted of 5 families of pigtail macaques producing 394 infants and 9 families of sooty mangabeys producing 535 infants. Infant neglect and abuse were identified with strict and conservative criteria. Neglect was identified when an observer witnessed mothers abandoning their infant before infant death or removal for medication and the infant's subsequent examination did not reveal any clinical condition other than starvation or dehydration. Abuse was identified when an observer witnessed mothers physically abusing their infant before infant death or removal and the infant's subsequent examination did not reveal any clinical condition other than physical trauma.

In both pigtail macaques and mangabeys, about $5 \%$ of all infants were abandoned by their mothers, and 5\%-10\% of them were severely abused. The 5 families of pigtail macaques differed significantly in the proportion of mothers that abused their offspring and in the proportion of infants that were abused. Moreover, in the 3 families in which abuse occurred, the coefficient of maternal relatedness between abusive mothers was higher than that between all of the other mothers, indicating that abuse was especially common among closely related females such as mothers and daughters or sisters. The mangabey data provided evidence for intrafamilial but not interfamilial genealogical effects on infant abuse. In the families with more than one abusive mother, abusive behavior was significantly more likely to be displayed by mothers and daughters than by other pairs of related females.

Infant abuse and neglect were associated with different demographic factors in both species. Infant neglect was essentially limited to young mothers and newborn infants, whereas infant abuse was unrelated to maternal experience or infant age. In both species, neglectful mothers neglected only one of their offspring, typically the first, whereas most abusive mothers repeated abuse with successive offspring. In both pigtails and mangabeys, some abusive mothers successfully raised some of their infants without any external intervention, and in the mangabeys, the birth order of severely abused infants was significantly higher than that of their siblings that survived without intervention. Therefore, in the mangabeys, the severity of infant abuse increased as a function of maternal parity. Infant sex and maternal infirmity were not risk factors for neglect or abuse.

Quantitative behavioral observations of infant neglect and abuse in group-living monkeys concur with the data obtained from colony records in indicating that neglect and abuse rarely occur together and are associated with different individual demographic and behavioral profiles. In a sample of 160 vervet monkey (Cercopithecus aethiops) mothers observed over a period of 10 years, infant abandonment or otherwise high levels of maternal rejection were most common among the youngest and the oldest females of low body weight (Fairbanks \& McGuire, 1995). There was no evidence, however, that mothers that frequently rejected or abandoned their infants also physically abused them. Infant abandonment by group-living primiparous mothers has also been reported in other studies (e.g., Dazey \& Erwin, 1976; Hird, Henrickson, \& Hendrickx, 1972).

Most of the behavioral data concerning infant abuse in group- living monkeys suggest that abuse is associated with maternal protectiveness and control rather than with indifference and neglect. Troisi, D'Amato, Fuccillo, and Scucchi (1982) reported the case of a group-living wild-born Japanese macaque that alternated competent caregiving behavior with infant abuse and abused to death all of its infants. The abusive mother scored higher than control mothers in the tendency to make contact with and restrain its infant; abuse occurred when the infant attempted to break contact with the mother or failed to respond to the mother's retrieval signals (Troisi \& D'Amato, 1984). The administration of an anxiolytic drug to the abusive mother resulted in a reduction in maternal protectiveness and infant abuse (Troisi \& D'Amato, 1991). Troisi, Aureli, Piovesan, and D'Amato (1989) reported the case of another female living in the same captive colony of Japanese macaques that abused all of its three infants. Also in this case, infant abuse was associated with protective maternal care, but abuse was not so severe as to cause infant death. This female had been abandoned after birth by its biological mother and adopted and reared by another female, a phenomenon not uncommon in macaques. Infant abuse by orphaned mothers was also observed in free-ranging Japanese macaques (Hiraiwa, 1981).

The parenting style of abusive mothers was systematically investigated in a recent study of rhesus macaques living in stable social groups (Maestripieri, 1998). Ten abusive mothers were identified in the large rhesus population housed at the Yerkes Primate Center and observed, along with 10 controls, over the first 12 weeks of infant life. Abusive mothers alternated appropriate caregiving behavior with short episodes of infant maltreatment. Abuse peaked in the 1st week and decreased thereafter, almost disappearing by the 12th week. Abusive mothers differed from controls in a number of parenting style measures. Abusive mothers spent a higher percentage of time in contact with their infants, initiated more contacts with them, and restrained them more often than control mothers. Abusive mothers also rejected their infants much more than controls. Although abusive and control mothers did not differ significantly in the amount of aggression received from other group members, abusive mothers tended to be more aggressive than controls. Abusive mothers also received fewer approaches from other individuals than controls and were more interested in the infants of other females than control mothers.

In rhesus macaques, abuse was not consistently associated with particular infant activities or external events. In groupliving pigtail macaques and vervet monkeys, however, infant abuse has often been observed to occur under conditions of stress such as conflicts or extragroup disturbances (Erwin, 1983; L. A. Fairbanks, personal communication, April 5, 1997; Maestripieri, 1994a; Maestripieri \& Carroll, in press). For example, in a well-documented case, maternal abusive behavior appeared in strict temporal association with the repeated kidnapping and severe harassment of the infant by another group member, abuse being absent before the appearance of stress and drastically reduced after its termination (Maestripieri, 1994a).

\section{Interpretation of the Findings}

The information obtained from long-term colony records indicates that about $5 \%-10 \%$ of pigtail macaque and mangabey 
infants are at risk of abuse and that neglect is less frequent than abuse. These results must be interpreted with caution, because only severe abuse was included and because neglect was equated with infant abandonment. The prevalence of abuse and neglect in these populations of monkeys is probably higher than reported, and the relative prevalence of neglect versus abuse may be different as well. Similarly, it cannot be ruled out that neglect was associated with mild abuse, or vice versa.

Despite these limitations in the interpretation of the data, the long-term colony records concur with the behavioral observations of group-living monkeys in suggesting that infant neglect and abuse may be different phenomena with independent causal factors. The main differences between neglect and abuse include the age and physical condition of the mother and the fact that abuse is repeated with successive infants, whereas neglect is not. Moreover, abuse is more likely to occur in certain families and among closely related females, whereas this is not the case for neglect. Lack of experience can be a proximate factor responsible for infant neglect by primiparous mothers, but it does not appear to play a role in the occurrence of abuse (see Ruppenthal et al., 1976, for similar findings with motherless mothers). Altogether, the evidence available suggests that, in most circumstances, infant abandonment in monkeys may be an adaptive response to circumstances unfavorable for parental care. In this view, infant abandonment in monkeys is similar to offspring abandonment in other animals and is consistent with parental investment theory. In contrast, the observation that abusive mothers appear to invest more time and energy in their infants than nonabusive mothers suggests that abuse is best viewed as a pathological phenomenon.

Several hypotheses can be advanced concerning the mechanisms underlying infant abuse. The interest shown by abusive mothers in newborn infants suggests that they are highly responsive to the stimulus characteristics (visual, auditory, olfactory, or tactile) of newborns. Abusive mothers, however, may have an initial difficulty in forming a strong and specific bond with their own infants. Alternatively, abusive mothers may form an immediate and strong bond with their infants but exhibit maladaptive processes in the emotional or cognitive regulation of parenting.

On the basis of observations of infant abuse in captive Japanese macaques and the effect of pharmacological treatment on abuse, Troisi and D'Amato (1994) emphasized anxious and possessive mothering as a possible determinant of infant abuse. Specifically, it was argued that abusive mothers may be anxiously attached to their infants and react with violence to their infants' attempts to gain independence from them. Troisi and D'Amato (1994) also attempted to generalize this explanation to infant abuse by motherless mothers and noted that some of these females had became very protective of their successive infants (Seay et al., 1964). In this view, anxious attachment in abusive mothers may originate from early separation from their own mothers and consequent fear of losing another attachment object, the infant (Bowlby, 1973; De Lozier, 1982). This explanation, however, seems to impute rather sophisticated cognitive processes to monkey mothers, for which there is no clear empirical support.

The study of parenting styles of abusive rhesus mothers showed that these females are more protective but also more rejecting than nonabusive mothers. Protectiveness and rejection are independent dimensions of parenting style in monkeys, and mothers who score high on both dimensions are classified as controlling (Fairbanks, 1996). The parenting style of abusive rhesus mothers and the observations made with Japanese macaques support the view that infant abuse may reflect inappropriate attempts to control the infant's behavior. Although the determinants of controlling parenting styles need to be further investigated, the available primate data suggest that an aggressive temperament, a low amount of social contact from other individuals, and stressful circumstances may contribute to both controlling parenting styles and infant abuse (Maestripieri, 1994a, 1998; Troisi \& D'Amato, 1984).

In the study of group-living rhesus macaques, all abusive mothers had been raised by their own mothers, and in most cases they were still living with them, suggesting that infant abuse is not necessarily preceded by an experience of separation or loss. However, half of the abusive mothers were closely related to another abusive mother, suggesting that genetic relatedness or shared environmental conditions with another abusive female may enhance the probability of abuse. The mechanisms for intergenerational transmission of infant abuse may include learning processes, continuity in psychological traits associated with abuse, or both. Studies of rhesus macaques and vervet monkeys have shown that mothering styles of individual females resemble those of their mothers and that similarities can be accounted for by direct experience of being mothered during infancy or by observational learning of interactions between the mother and younger siblings (Berman, 1990; Fairbanks, 1989). Thus, it is possible that patterns of abusive behavior could be transmitted across generations with mechanisms similar to the intergenerational transmission of mothering styles. It is also possible, however, that the mechanisms underlying the transmission of abuse across generations are different from those that trigger the onset of abuse in some individuals.

The observation that, in most cases, abuse and neglect appear as early as the 1st day of infant life, when infants are behaviorally passive, argues against the hypothesis that infants contribute significantly to the occurrence of abuse or neglect. Although abused and neglected infants did not exhibit any obvious physical or behavioral handicaps, it cannot be ruled out that they had other deficits or abnormalities that could contribute to abuse. Laboratory and field studies of blind infants, however, showed that monkey mothers exhibited a great deal of compensatory care for handicapped infants (Berkson, 1973), suggesting that handicaps do not necessarily increase the probability of abuse or neglect. The observation that abusive mothers tend to abuse most if not all of their infants also suggests that the infant's role in triggering abuse may be negligible. Emphasis on the role of mothers in the occurrence of abuse and neglect is generally consistent with the notion that differences in mother-infant relationships in monkeys are largely accounted for by differences in maternal rather than in infant characteristics (Fairbanks, 1996). In this view, infant maltreatment is seen on a continuum of parenting quality ranging from controlling to laissez-faire to abuse and neglect.

So far, information on the spontaneous occurrence of infant abuse and neglect exists only in a small percentage of the 186 extant species of primates. Even among these few species, how- 
ever, there are some indications that this phenomenon may have species-specific characteristics. For example, infant abuse was clearly observed under stressful circumstances in pigtail macaques but not in rhesus macaques. Differences in temperament between species may be responsible for these differences (Clarke \& Boinski, 1995); for example, pigtail macaques have generally been described as relatively timid animals that are easily disturbed by human presence or environmental changes (Bernstein, 1967; Caldecott, 1987), whereas rhesus macaques are known for their boldness and aggressiveness with both conspecifics and humans (Richard, Goldstein, \& Dewar, 1989).

\section{Relevance to Child Maltreatment}

The spontaneous occurrence of infant abuse and neglect in group-living monkeys is a phenomenon that shares some similarities as well as differences with child abuse and neglect. The similarities concern the overall prevalence of infant abuse and neglect in primate and human populations, the transmission of abuse across generations, the relation between infant age and abuse, some psychological and behavioral characteristics of abusive parents, and the potential role of social stress in triggering abuse. In addition to obvious differences concerning social, cultural, and cognitive influences on primate and human child maltreatment, some differences between primate and human data have also emerged with regard to the relation between abuse and neglect and the role of infant characteristics in triggering abuse or neglect. Because the investigation of the spontaneous occurrence of infant abuse and neglect is just beginning, it is possible that future studies of this phenomenon will highlight further similarities or differences with child abuse and neglect.

The prevalence of infant abuse and neglect in monkey and human populations appears to be within the same order of magnitude, about $10 \%$ (National Center on Child Abuse and Neglect, 1995). Furthermore, in both primates and humans, the prevalence of abuse and neglect is likely to be higher than reported. In monkeys, abuse seems to be more frequent than neglect, whereas the opposite is true for humans. However, this discrepancy may be related to the use of conservative criteria for the identification of neglect in monkeys (i.e., the equation of neglect with abandonment). Clearly, to make more precise comparisons between primates and humans, similar definitions of infant abuse and neglect as well as similar methods of gathering information need to be used.

Although the primate findings are still preliminary, monkeys and humans appear to share what is perhaps the most striking characteristic of infant maltreatment: its transmission across generations (Egeland, Jacobvitz, \& Papatola, 1987; Kaufman \& Zigler, 1989). In both humans and primates, the most likely mechanism of transmission could involve learning behavior patterns or styles of interaction during childhood and then expressing them during adulthood in the parenting role. The most direct learning pathway would stem from a direct experience of abuse, but learning could also occur by exposure to other relationships within the family. Other traumatic events such as parental separation or loss that occur during infancy may be present in the developmental history of some primate and human parents who abuse their infants (e.g., Hall, Pawlby, \& Wolkind, 1979), but they are probably best viewed as contributing factors rather than as determinants of infant maltreatment. The same argument could be valid for stress experienced during adulthood: Social stress may play a role in triggering infant maltreatment, but neither the primate nor the human data indicate that social stress alone can reliably predict the occurrence of maltreatment.

In primates, as in humans, abusive parents do not necessarily show signs of obvious psychological and social pathologies, although they may experience some degree of social isolation from other members of their group or community (Garbarino, 1977). In Japanese and rhesus macaques, as in humans, abuse seems to originate from the use of violent and coercive methods to control the infant's behavior (Herrenkhol, Herrenkhol, Toedter, \& Yanushevsky, 1984; Oldershaw, Walters, \& Hall, 1986). The parenting styles of abusive human parents show considerable variability, ranging from the authoritarian (high in demandingness and low in responsiveness) to the neglecting (low in demandingness and low in responsiveness) categories, perhaps because abuse and neglect are often combined (e.g., Oldershaw et al., 1986; Sloan \& Meier, 1983). The hypothesis that extreme maternal anxiety may be implicated in primate infant abuse is consistent with the notion that problems in emotion regulation are also often found in abusive human parents (Lahey, Conger, Atkenson, \& Treiber, 1984; Rogosch et al., 1995). Interestingly, the personality traits that are more consistently associated with abuse, such as anxiety and hostility, are also highly heritable (Plomin, 1986), suggesting that biologically determined consistency in personality dimensions could contribute to the intergenerational transmission of abuse.

One of the characteristics that seems to set apart the primate from the human phenomenon is the relation between neglect and abuse. In primates, abuse and neglect appear to be clearly distinct in terms of risk factors and circumstances of occurrence, suggesting that the two phenomena may have different biological functions and be regulated by different mechanisms. In humans, many parents both abuse and neglect their offspring, and most studies combine both types of maltreatment (Belsky, 1993). In the few studies in which abusive and neglectful parents were distinguished, however, important differences emerged in parental personality traits and styles of interactions with their children (Crittenden, 1981; Crittenden \& Ainsworth, 1989). Anxiety and hostility are common in abusive parents and are often associated with an authoritarian parenting style. In contrast, depression and a parenting style low in demandingness and responsiveness are common among neglectful parents. From an attachment theory perspective, abusive parents often have internal representational models based on power, conflict, control, and rejection, whereas neglectful parents have internal representational models organized around helplessness (Crittenden \& Ainsworth, 1989). Because of these differences, researchers such as Belsky (1993) have recently stated that "it would be ideal in the course of examining the research on the etiology of physical child abuse and neglect to be able to make frequent distinctions between these two forms of maltreatment"' (p. 413).

Insofar as the primate data emphasize the role of the parent over that of the infant in the causation of infant abuse, they seem to be more consistent with the early psychopathology models of child maltreatment than with more recent interactional models. Several human studies have indicated that children with certain physical and behavioral characteristics, such as prematurity, low 
birthweight, mental retardation, difficult temperament, and disruptive behavior, are more likely to be abused than other children (Rogosch et al., 1995). The results of some of these studies, however, have been questioned on the grounds that abusive parents report more problem behavior on the part of their children than more objective observers (e.g., Reid, Kavanagh, \& Baldwin, 1987). Therefore, some authors seem inclined to attribute a larger role in the etiology of maltreatment to parents than to their children, although not denying that children may inadvertently contribute to some instances of maltreatment (e.g., Belsky, 1993; Cicchetti, 1996).

Overall, there appear to be enough similarities between the spontaneous occurrence of infant abuse - and perhaps also neglect -in monkeys and child maltreatment in humans to warrant a further and more systematic investigation of the primate data. Particularly, it would be important to assess whether or not infant abuse and neglect would spontaneously occur among primates that are more closely related to humans, such as the great apes (bonobos [ $P$ an paniscus], chimpanzees, gorillas, and orangutans [Pongo pygmaeus]), and whether or not they would share those characteristics observed in monkeys. Differences among primate species in some characteristics of infant abuse and neglect do not necessarily imply that certain species may be better than others as a model for child abuse. Rather, they provide encouragement to conduct comparative research in a wider number of species and to understand the general principles governing the relationships between biological, psychological, and social variables and infant maltreatment, regardless of the specific patterns of occurrence of maltreatment in each species.

\section{Conclusion and Future Research Directions}

A number of phenomena occurring in several animal taxa share some characteristics with child abuse and neglect. Perhaps the clearest link among animal data, evolutionary theory, and child maltreatment is that offspring neglect or abandonment is predicted and actually observed in circumstances unfavorable for parental care. Therefore, animal research and its theoretical extrapolations can provide useful information for understanding the circumstances in which human parents drastically reduce or terminate investment in their children. Although, in a number of animal species, adaptive termination of parental investment may also take the form of offspring destruction and cannibalism, it is not clear whether child physical abuse can be directly compared with these phenomena. In fact, child abuse very likely reflects a dysfunction of mechanisms and processes underlying parenting rather than an adaptive response to environmental circumstances.

The spontaneous occurrence of infant abuse and neglect in monkeys is probably the closest approximation to child maltreatment provided by nonhuman animals. Infant maltreatment in primates is therefore a promising animal model for investigating child abuse and neglect without the ethical and practical limitations that accompany research with humans. Longitudinal studies of group-living monkeys in the field and in captivity can provide important information on factors affecting the distribution of infant maltreatment in the study populations and its transmission across generations. They can also provide specific information on maltreating mother-infant dyads within their social environment. Further investigation of variability in parenting styles and its determinants (see Fairbanks, 1996) may be particularly relevant to an understanding of the causes of infant maltreatment. For example, an understanding of how mothers adopt or modify their parenting style in relation to early experience, personality characteristics, or environmental factors may elucidate the mechanisms by which certain individuals acquire the characteristics that put them at risk of abusing their offspring. Further insight into the causes of infant abuse could also be obtained by integrating information on the mother's developmental history and personality characteristics with information on the quality of the mother-infant relationship, the infant's characteristics, and the environmental circumstances in which maltreatment occurs.

Epidemiological and observational studies of infant abuse in monkeys can be integrated with experimental manipulations. The relative role of biological and experiential factors in the intergenerational transmission of infant maltreatment could be investigated by cross fostering infants between maltreating and nonmaltreating mothers and then investigating the parenting behavior of these individuals when they give birth to their own infants. The potential biological correlates of dysfunctional parenting could be investigated with the measurement of endocrine, neurochemical, and neural activity in maltreating mothers. The role of maternal emotionality and infant activity could be assessed through pharmacological alterations of maternal and infant behavior. The role of social stress in precipitating abuse could be investigated by examining the short- and long-term maternal and infant responses to stressors similar to those encountered by primates in their social environment.

Although some scientists may find it easier to study primates in a simplified social environment, experimental studies of behavior and physiology conducted in large social groups in captivity and in the wild are feasible and greatly enhance the validity of the findings obtained. Investigation of the causes of infant maltreatment in primates could encourage the integration of laboratory and field studies, of observation and manipulation, and of behavioral and physiological analyses. The results of this enterprise could make a significant contribution to an understanding of the etiology of child maltreatment, with important implications for prevention and treatment as well.

\section{References}

Arling, G. L., \& Harlow, H. F. (1967). Effects of social deprivation on maternal behavior of rhesus monkeys. Journal of Comparative and Physiological Psychology, 64, 371-377.

Armstrong, T., \& Robertson, R. J. (1988). Parental investment based on clutch value: Nest desertion in response to partial clutch loss in dabbling ducks. Animal Behaviour, 36, 941-943.

Barnett, D., Manly, J. T., \& Cicchetti, D. (1993). Defining child maltreatment: The interface between policy and research. In D. Cicchetti \& S. L. Toth (Eds.), Child abuse, child development, and social policy (pp. 7-73). Norwood, NJ: Ablex.

Belsky, J. (1980). Child maltreatment: An ecological integration. American Psychologist, 35, 320-335.

Belsky, J. (1993). Etiology of child maltreatment: A developmentalecological analysis. Psychological Bulletin, 114, 413-434.

Berkson, G. (1973). Social responses to abnormal infant monkeys. American Journal of Physical Anthropology, 38, 583-586. 
Berman, C. M. (1990). Consistency in maternal behavior within families of free-ranging rhesus monkeys: An extension of the concept of maternal style. American Journal of Primatology, 22, 159-169.

Bernstein, I. S. (1967). A field study of the pigtail monkey (Macaca nemestrina). Primates, 8, 217-228.

Birkhead, T. R. (1978). Behavioural adaptations to high density nesting in the common guillemot Uria aalge. Animal Behaviour, 26, 321331.

Bowlby, J. (1973). Attachment and loss: Vol. 2. Separation. New York: Basic Books.

Caine, N. G., \& Reite, M. (1983). Infant abuse in captive pigtailed macaques: Relevance to human child abuse. In M. Reite \& N. G. Caine (Eds.), Child abuse: The nonhuman primate data (pp. 1927). New York: Alan R. Liss.

Caldecott, J. O. (1987). An ecological and behavioural study of the pigtailed macaque. Basel, Switzerland: Karger.

Castell, R., \& Wilson, C. (1971). Influence of spatial environment on development of mother-infant interaction in pigtail monkeys. Behaviour, 39, 202-211.

Cicchetti, D. (1996). Child maltreatment: Implications for developmental theory and research. Human Development, 39, 18-39.

Cicchetti, D., \& Rizley, R. (1981). Developmental perspectives on the etiology, intergenerational transmission, and sequelae of child maltreatment. New Directions for Child Development, 11, 31-55.

Cicchetti, D., \& Toth, S. L. (1995). A developmental psychopathology perspective on child abuse and neglect. Journal of the American Academy of Child and Adolescent Psychiatry, 34, 541-565.

Clarke, A. S., \& Boinski, S. (1995). Temperament in nonhuman primates. American Journal of Primatology, 36, 1-23.

Clutton-Brock, T. H. (1991). The evolution of parental care. Princeton, NJ: Princeton University Press.

Crittenden, P. M. (1981). Abusing, neglecting, problematic, and adequate dyads: Differentiating by patterns of interaction. Merrill-Palmer Quarterly, 27, 201-208.

Crittenden, P. M., \& Ainsworth, M. (1989). Child maltreatment and attachment theory. In D. Cicchetti \& V. Carlson (Eds.), Child maltreatment: Theory and research on the causes and consequences of child abuse and neglect (pp. 432-463). New York: Cambridge University Press.

Daly, M., \& Wilson, M. I. (1981). Abuse and neglect of children in evolutionary perspective. In R. D. Alexander \& D. W. Tinkle (Eds.), Natural selection and social behavior (pp. 404-416). New York: Chiron Press.

Davenport, R. K. (1979). Some behavioral disturbances of great apes in captivity. In D. A. Hamburg \& E. R. McCown (Eds.), The great apes (pp. 341-357). Menlo Park, CA: Benjamin Cummins.

Davenport, R. K., \& Rogers, C. M. (1970). Differential rearing of the chimpanzee: A project survey. In G. H. Bourne (Ed.), The chimpanzee (Vol. 3, pp. 337-360). Basel, Switzerland: Karger.

Day, C. S. D., \& Galef, B. G. (1977). Pup cannibalism: One aspect of maternal behavior in golden hamsters. Journal of Comparative and Physiological Psychology, 91, 1179-1189.

Dazey, J., \& Erwin, J. (1976). Infant mortality in Macaca nemestrina: Neonatal and postnatal mortality at the Regional Primate Research Center Field Station at the University of Washington, 1967-1974. Theriogenology, 5, 267-279.

De Lozier, P. P. (1982). Attachment theory and child abuse. In C. Parkes \& J. Stevenson-Hinde (Eds.), The place of attachment in human behavior (pp. 95-117). New York: Basic Books.

Dienske, H., van Vreeswijk, W., \& Koning, H. (1980). Adequate mothering by partially isolated rhesus monkeys after observation of maternal care. Journal of Abnormal Psychology, 89, 489-492.

Dominey, W. J., \& Blumer, L. B. (1984). Cannibalism of early life stages in fish. In G. Hausfater \& S. B. Hrdy (Eds.), Infanticide:
Comparative and evolutionary perspectives (pp. 43-64). New York: Aldine.

Egeland, B., Jacobvitz, D., \& Papatola, K. (1987). Intergenerational continuity of abuse. In R. J. Gelles \& J. B. Lancaster (Eds.), Child abuse and neglect. Biosocial dimensions (pp. 255-276). New York: Aldine.

Erwin, J. (1983). Primate infant abuse: Communication and conflict. In M. Reite \& N. G. Caine (Eds.), Child abuse: The nonhuman primate data (pp. 79-102). New York: Alan R. Liss.

Fairbanks, L. A. (1989). Early experience and cross-generational continuity of mother-infant contact in vervet monkeys. Developmental Psychobiology, 22, 669-681.

Fairbanks, L. A. (1996). Individual differences in maternal styles: Causes and consequences for mothers and offspring. Advances in the Study of Behavior, 25, 579-611.

Fairbanks, L. A., \& McGuire, M. T. (1995). Maternal condition and the quality of maternal care in vervet monkeys. Behaviour, 132, 733754.

Gandelman, R., \& Simon, N. G. (1978). Spontaneous pup-killing by mice in response to large litters. Developmental Psychobiology, 11, 235-241.

Garbarino, J. (1977). The human ecology of child maltreatment: A conceptual model for research. Journal of Marriage and the Family, $39,721-732$.

Gelles, R. J. (1973). Child abuse and psychopathology: A sociological critique and reformulation. American Journal of Orthopsychiatry, 43, 611-621.

Gil, D. (1970). Violence against children: Physical child abuse in the United States. Cambridge, MA: Harvard University Press.

Gosling, L. M. (1986). Selective abortion of entire litters in the coypu: Adaptive control of offspring production in relation to quality and sex. American Naturalist, 127, 772-795.

Hall, F., Pawlby, S., \& Wolkind, S. (1979). Early life experiences and later mothering behavior: A study of mothers and their 20 week old babies. In D. Schaffer \& J. Dunn (Eds.), The first year of life (pp. 153-174). New York: Wiley.

Harlow, H. F., \& Harlow, M. K. (1962). The effect of rearing conditions on behavior. Bulletin of the Menninger Clinic, 26, 213-224.

Harlow, H. F., Harlow, M. K., Dodsworth, R. O., \& Arling, G. L. (1966). Maternal behavior of rhesus monkeys deprived of mothering and peer associations in infancy. Proceedings of the American Philosophical Society, 110, 58-66.

Harlow, H. F., \& Seay, B. (1966). Mothering in motherless mother monkeys. British Journal of Sociology and Psychiatry, 1, 63-69.

Hausfater, G., \& Hrdy, S. B. (Eds.). (1984). Infanticide: Comparative and evolutionary perspectives. New York: Aldine.

Herrenkhol, E. C., Herrenkhol, R. C., Toedter, L., \& Yanushevsky, M. (1984). Parent-child interactions in abusive and nonabusive families. Journal of the American Academy of Child Psychiatry, 23, 641-648.

Hinde, R. A., \& Spencer-Booth, Y. (1967). The behaviour of socially living rhesus monkeys in their first two and a half years. Animal Behaviour, 15, 169-196.

Hiraiwa, M. (1981). Maternal and alloparental care in a troop of freeranging Japanese monkeys. Primates, 22, 309-329.

Hird, D. W., Henrickson, R. V., \& Hendrickx, A. G. (1972). Infant mortality in Macaca mulatta: Neonatal and post-natal mortality at the California Primate Research Center, 1968-1972. Journal of Medical Primatology, 4, 8-22.

Horenstein, D. (1977). The dynamics and treatment of child abuse: Can primate research provide the answers? Journal of Clinical Psychology, 33, 563-565.

Hrdy, S. B. (1979). Infanticide among mammals: A review, classification, and examination of the implications for the reproductive strategies of females. Ethology and Sociobiology, 1, 13-40. 
Jensen, G. D., Bobbitt, R. A., \& Gordon, B. N. (1969). Patterns and sequences of hitting behavior in mother and infant monkeys (Macaca nemestrina). Journal of Psychiatric Research, 7, 55-61.

Kaplan, J. N. (1972). Differences in the mother-infant relations of squirrel monkeys housed in social and restricted environments. Developmental Psychobiology, 5, 43-52.

Kaufman, J., \& Zigler, E. (1989). The intergenerational transmission of child abuse: In D. Cicchetti \& V. Carlson (Eds.), Child maltreatment: Theory and research on the causes and consequences of child abuse and neglect (pp. 129-150). New York: Cambridge University Press.

Kempe, C. H., Silverman, F. N., Steele, B. B., Droegemueller, W., \& Silver, H. K. (1962). The battered child syndrome. Journal of the American Medical Association, 181, 17-24.

König, B. (1989). Kin recognition and maternal care under restricted feeding in house mice. Ethology, 82, 328-343.

Lahey, B. B., Conger, R. D., Atkenson, B. M., \& Treiber, F. A. (1984). Parenting behavior and emotional status of physically abusive mothers. Journal of Consulting and Clinical Psychology, 52, 1062-1071.

Lenington, S. (1981). Child abuse: The limits of sociobiology. Ethology and Sociobiology, 2, 17-29.

Lightcap, J. L., Kurland, J. A., \& Burgess, R. L. (1982). Child abuse: A test of some predictions derived from evolutionary theory. Ethology and Sociobiology, 3, 61-67.

Maestripieri, D. (1991). Litter gender composition, food availability, and maternal defence of the young in house mice (Mus domesticus). Behaviour, 116, 139-151.

Maestripieri, D. (1992). Functional aspects of maternal aggression in mammals. Canadian Journal of Zoology, 70, 1069-1077.

Maestripieri, D. (1993a). Maternal anxiety in rhesus macaques (Macaca mulatta). I. Measurement of anxiety and identification of anxietyeliciting situations. Ethology, 95, 19-31.

Maestripieri, D. (1993b). Maternal anxiety in rhesus macaques (Macaca mulatta). II. Emotional bases of individual differences in mothering style. Ethology, 95, 32-42.

Maestripieri, D. (1994a). Infant abuse associated with psychosocial stress in a group-living pigtail macaque (Macaca nemestrina) mother. American Journal of Primatology, 32, 41-49.

Maestripieri, D. (1994b). Social structure, infant handling, and mothering styles in group-living Old World monkeys. International Journal of Primatology, 15, 531-553.

Maestripieri, D. (1995a). Assessment of danger to themselves and their infants by rhesus macaque (Macaca mulatta) mothers. Journal of Comparative Psychology, 109, 416-420.

Maestripieri, D. (1995b). First steps in the macaque world: Do rhesus mothers encourage their infants' independent locomotion? Animal Behaviour, 49, 1541-1549.

Maestripieri, D. (1996). Maternal encouragement of infant locomotion in pigtail macaques (Macaca nemestrina). Animal Behaviour, 51, 603-610.

Maestripieri, D. (1998). Parenting styles of abusive mothers in groupliving rhesus macaques. Animal Behaviour, 55, 1-11.

Maestripieri, D., \& Call, J. (1996). Mother-infant communication in primates. Advances in the Study of Behavior, 25, 613-642.

Maestripieri, D., \& Carroll, K. A. (in press). Behavioral and environmental correlates of infant abuse in group-living pigtail macaques. Infant Behavior and Development.

Maestripieri, D., Wallen, K., \& Carroll, K. A. (1997a). Infant abuse runs in families of group-living pigtail macaques. Child Abuse \& Neglect, 21, 465-471.

Maestripieri, D., Wallen, K., \& Carroll, K. A. (1997b). Genealogical and demographic influences on infant abuse and neglect in groupliving sooty mangabeys (Cercocebus atys). Developmental Psychobiology, 31, 175-180.

Malkin, C. M., \& Lamb, M. E. (1994). Child maltreatment: A test of sociobiological theory. Journal of Comparative Family Studies, 25 , 121-133.

McClure, P. A. (1981). Sex-biased litter reduction in food-restricted wood rats (Neotoma floridana). Science, 211, 1058-1060.

Mendl, M. (1994). How should parents respond to a reduction in litter size? Abandonment or extra care? Behavioural Processes, 31, 285292.

Miller, R. E., Caul, W. F., \& Mirsky, I. A. (1967). Communication of affects between feral and socially isolated monkeys. Journal of Personality and Social Psychology, 7, 231-240.

Mitchell, G. D., Raymond, E. J., Ruppenthal, G. C., \& Harlow, H. F. (1966). Long-term effects of social isolation upon behavior of rhesus monkeys. Psychological Reports, 18, 567-580.

Mock, D. W. (1984). Infanticide, siblicide, and avian nesting mortality. In G. Hausfater \& S. B. Hrdy (Eds.), Infanticide: Comparative and evolutionary perspectives (pp. 3-30). New York: Aldine.

Mock, D. W., \& Parker, G. A. (1986). Advantages and disadvantages of egret and heron brood reduction. Evolution, 40, 459-470.

Mrwoka, W. (1987). Filial cannibalism and reproductive success in the maternal mouthbrooding cichlid fish Pseudocrenilabrus multicolor. Behavioral Ecology and Sociobiology, 21, 257-265.

Mumme, R. L., Koenig, W. D., \& Pitelka, F. A. (1983). Reproductive competition in the communal acorn woodpecker: Sisters destroy each other's eggs. Nature, 306, 583-584.

Nadler, R. D. (1980). Child abuse: Evidence from nonhuman primates. Developmental Psychobiology, 13, 507-512.

Nadler, R. D. (1983). Experiential influences on infant abuse of gorillas and some other nonhuman primates. In M. Reite \& N. G. Caine (Eds.), Child abuse: The nonhuman primate data (pp. 139-149). New York: Alan R. Liss.

National Center on Child Abuse and Neglect. (1995). Child maltreatment-1993. Washington, DC: U.S. Department of Health and Human Services.

Negayama, K. (1981). Maternal aggression to its offspring in Japanese macaques. Journal of Human Evolution, 10, 523-527.

Oldershaw, L., Walters, G. C., \& Hall, D. K. (1986). Control strategies and noncompliance in abusive mother-child dyads. Child Development, 57, 722-732.

Plomin, R. (1986). Development, genetics, and psychology. Hillsdale, NJ: Erlbaum.

Reid, J. B., Kavanagh, K., \& Baldwin, D. V. (1987). Abusive parents' perceptions of child problem behaviors: An example of parental bias. Journal of Abnormal Child Psychology, 15, 457-466.

Reite, M. (1987). Infant abuse and neglect: Lessons from the primate laboratory. Child Abuse and Neglect, 11, 347-355.

Reite, M., \& Caine, N. G. (Eds.). (1983). Child abuse: The nonhuman primate data. New York: Alan R. Liss.

Reite, M., \& Capitanio, J. P. (1987). Child abuse: A comparative and psychobiological perspective. In R. J. Gelles \& J. B. Lancaster (Eds.), Child abuse and neglect. Biosocial dimensions (pp. 149-174). New York: Aldine.

Richard, A. F., Goldstein, S. J., \& Dewar, R. E. (1989). Weed macaques: The evolutionary implications of macaque feeding ecology. International Journal of Primatology, 10, 569-594.

Rogers, C. M., \& Davenport, R. K. (1970). Chimpanzee maternal behavior. In G. H. Bourne (Ed.), The chimpanzee (pp. 361-368). Basel, Switzerland: Karger.

Rogosch, F. A., Cicchetti, D., Shields, A., \& Toth, S. L. (1995). Parenting dysfunction in child maltreatment. In M. H. Bornstein (Ed.), Handbook of parenting (Vol. 4, pp. 127-159). Mahwah, NJ: Erlbaum.

Rosenblatt, J. S., \& Snowdon, C. T. (Eds.). (1996). Parental care: Evolution, mechanisms, and adaptive significance. New York: Academic Press. 
Ruppenthal, G. C., Arling, G. L., Harlow, H. F., Sackett, G. P., \& Suomi, S. J. (1976). A 10-year perspective of motherless-mother monkey behavior. Journal of Abnormal Psychology, 85, 341-349.

Sackett, G. P. (1965). Effects of rearing conditions upon monkeys. Child Development, 35, 855-868.

Schapiro, S. J., \& Mitchell, G. (1983). Infant-directed abuse in a seminatural environment: Precipitating factors. In M. Reite \& N. G. Caine (Eds.), Child abuse: The nonhuman primate data (pp. 29-48). New York: Alan R. Liss.

Seay, B., Alexander, B. K., \& Harlow, H. F. (1964). Maternal behavior of socially deprived rhesus monkeys. Journal of Abnormal and Social Psychology, 69, 345-354.

Sloan, M., \& Meier, J. (1983). Typology for parents of abused children. Child Abuse and Neglect, 7, 443-450.

Smuts, B. B., Cheney, D. L., Seyfarth, R. M., Wrangham, R. W., \& Struhsaker, T. T. (Eds.). (1987). Primate societies. Chicago: University of Chicago Press.

Spinetta, J. J., \& Rigler, D. (1972). The child-abusive parent: A psychological review. Psychological Bulletin, 77, 296-304.

Steele, B. F., \& Pollack, C. B. (1968). A psychiatric study of parents who abuse infants and small children. In R. E. Helfer \& C. H. Kempe (Eds.), The battered child (pp. 89-133). Chicago: University of Chicago Press.

Straus, M. A., Gelles, R. J., \& Steinmetz, S. (1980). Behind closed doors: Violence in American families. Garden City, NY: Anchor/ Doubleday.

Struhsaker, T. T., \& Leland, L. (1987). Colobines: Infanticide by adult males. In B. B. Smuts, D. L. Cheney, R. M. Seyfarth, R. W. Wrangham, \& T. T. Struhsaker (Eds.), Primate societies (pp. 83-97). Chicago: University of Chicago Press.

Suomi, S. J. (1978). Maternal behavior by socially incompetent monkeys: Neglect and abuse of offspring. Journal of Pediatric Psychology, 3, 28-34.

Suomi, S. J., \& Ripp, C. (1983). A history of motherless mother monkey mothering at the University of Wisconsin Primate Laboratory. In M. Reite \& N. G. Caine (Eds.), Child abuse: The nonhuman primate data (pp. 49-78). New York: Alan R. Liss.

Tait, D. E. N. (1980). Abandonment as a reproductive tactic: The example of grizzly bears. American Naturalist, 112, 800-808.

Trivers, R. L. (1972). Parental investment and sexual selection. In B. Campbell (Ed.), Sexual selection and the descent of man (pp. 136179). Chicago: Aldine.
Trivers, R. L. (1974). Parent-offspring conflict. American Zoologist, 14, 249-264.

Troisi, A., Aureli, F., Piovesan, P., \& D'Amato, F. R. (1989). Severity of early separation and later abusive mothering in monkeys: What is the pathogenic threshold? Journal of Child Psychology and Psychiatry, 30, 277-284.

Troisi, A., \& D'Amato, F. R. (1983). Is monkey maternal abuse of offspring aggressive behavior? Aggressive Behavior, 9, 167-173.

Troisi, A., \& D'Amato, F. R. (1984). Ambivalence in monkey mothering: Infant abuse combined with maternal possessiveness. Journal of Nervous and Mental Disease, 172, 105-108.

Troisi, A., \& D'Amato, F. R. (1991). Anxiety in the pathogenesis of primate infant abuse: A pharmacological study. Psychopharmacology, 103, 571-572.

Troisi, A., \& D'Amato, F. R. (1994). Mechanisms of primate infant abuse: The maternal anxiety hypothesis. In S. Parmigiani \& F. vom Saal (Eds.), Infanticide and parental care (pp. 199-210). London: Harwood.

Troisi, A., D’Amato, F. R., Fuccillo, R., \& Scucchi, S. (1982). Infant abuse by a wild-born group-living Japanese macaque mother. Journal of Abnormal Psychology, 91, 451-456.

Vehrencamp, S. L. (1977). Relative fecundity and parental effort in communally nesting anis Crotophoga sulcirostris. Science, 197, 403405.

vom Saal, F. S., \& Howard, L. S. (1982). The regulation of infanticide and parental behavior: Implications for reproductive success in male mice. Science, 215, 1270-1272.

Wasser, S. K., \& Barash, D. P. (1983). Reproductive suppression among female mammals: Implications for biomedicine and sexual selection theory. Quarterly Review of Biology, 58, 513-538.

Wickler, W., \& Seibt, U. (1983). Optimal maternal care. Zeitschrift für Tierpsychologie, 63, 201-205.

Widom, C. S. (1989). The cycle of violence. Science, 244, 160-166.

Wolfe, D. A. (1985). Child abusive parents: An empirical review and analysis. Psychological Bulletin, 97, 462-482.

Wolfe, D. A. (1987). Child abuse: Implications for child development and psychopathology. Newbury Park, CA: Sage.

Wolfheim, J. H., Jensen, G. D., \& Bobbitt, R. A. (1970). Effects of group environment on the mother-infant relationship in pigtailed monkeys (Macaca nemestrina). Primates, 11, 119-124.

Received October 30, 1996

Revision received August 26, 1997

Accepted August 28, 1997 